\title{
Sometimes noise is beneficial: stream noise informs vocal communication in the little torrent frog Amolops torrentis
}

\author{
Longhui Zhao ${ }^{1,2} \cdot$ Bicheng Zhu',2 Jichao Wang $^{3} \cdot$ Steven E. Brauth $^{4}$. \\ Yezhong Tang ${ }^{1} \cdot$ Jianguo Cui $^{1}$
}

Received: 1 November 2016/Accepted: 5 April 2017/Published online: 18 April 2017

(C) Japan Ethological Society and Springer Japan 2017

\begin{abstract}
Many kinds of environmental noise can interfere with acoustic communication and efficient decision making in terrestrial species. Here we identified an exception to this generalization in a streamside species, the little torrent frog (Amolops torrentis) which communicates in a stream noise environment. To determine whether stream noise can act as a cue regarding the microhabitat characteristics of senders, we performed phonotaxis experiments using stimulus pairs constructed with synthetic male calls (high or low dominant frequency) and stream noise with varied signal-to-noise ratios. We found that females prefer calls with high amplitude stream noise added compared to those with low amplitude stream noise added for both high and low dominant frequency stimulus pairs; however, stream noise itself was not attractive in the absence of calls. These results show that stream noise can function as a cue that may be used by females for enhancing the attractiveness of
\end{abstract}

Electronic supplementary material The online version of this article (doi:10.1007/s10164-017-0515-y) contains supplementary material, which is available to authorized users.

Jianguo Cui

cuijg@cib.ac.cn; cuijgcn@gmail.com

Jichao Wang

wjc@hainnu.edu.cn

1 Chengdu Institute of Biology, Chinese Academy of Sciences, Chengdu 610041, Sichuan, China

2 University of Chinese Academy of Sciences, Beijing 100049, China

3 Ministry of Education Key Laboratory for Tropical Plant and Animal Ecology, College of Life Sciences, Hainan Normal University, Haikou 571158, Hainan, China

4 Department of Psychology, University of Maryland, College Park, MD 20742, USA calls. Stream noise associates closely with rocks, topographies and vegetation and may thus provide useful microhabitat information for signal receivers, thereby acting on sexual selection. These data therefore contribute to our understanding of how the perception of mate attractiveness in heterogeneous ecological environments can evolve.

Keywords Sound communication · Microhabitat . Amolops torrentis - Mate attractiveness - Sexual selection

\section{Introduction}

Acoustic signals can be transmitted over long distances through varied habitats and can convey many kinds of information concerning species and individual identity, sexual receptivity and spatiotemporal information (Tyack 1998; Marler and Slabbekoorn 2004; Wells and Schwartz 2007). Most terrestrial species rely heavily on acoustic signals to attract mates, assess risks and defend resources (Bernal et al. 2007; Linhart et al. 2012; Halfwerk et al. 2014). However, sound communication is often degraded by various biotic and abiotic sources of environmental noise which interfere with the transmission of acoustic signals as well as the detection and processing of information contained in these signals (Wiley and Richards 1982; Rabin and Greene 2002; Brumm and Slabbekoorn 2005; Brumm and Naguib 2009; Love and Bee 2010). These challenges drive selection pressures, resulting in the evolution of specialized morphological, behavioral and physiological adaptations for coping with environment noise interference (Slabbekoorn and Peet 2003; Feng et al. 2006; Fuller et al. 2007; Brumm and Zollinger 2011).

Most research on the impact of noise has focused on the detrimental effects and how animals deal with interference 
from noise. Nevertheless, noise can also be beneficial to some species, depending on the context and how receivers react to it (Stansbury et al. 2016). For instance, greater mouse-eared bats (Myotis myotis) and western scrub jays (Aphelocoma californica) have been shown to experience decreased predation pressure when predators avoid increased local noise produced by anthropogenic activity (Schaub et al. 2008; Francis et al. 2009). Anthropogenic noise can also be a form of acoustic crypsis and may increase the foraging success of predators by interfering with detection by prey (Chan et al. 2010).

In socially aggregating animals, competing biotic noise can mask vocal communication signals, interfering with signal detection, localization and recognition (Lohr et al. 2003; Feng and Schul 2007). However, biotic noise can also be used for orientation in the field because dense choruses can transmit communication sounds over long distances that remain detectable and identifiable (Gerhardt and Klump 1988; Sinsch 1990). The cooperative hypothesis proposes that conspecific background noise (i.e., synchronous calling) may also benefit males by disturbing the localization of individuals to predators and by increasing the group attractiveness to females (Grafe 1999). In addition to the possible benefits of anthropogenic and natural biotic noise, some studies indicate that natural abiotic noise may also be useful in some animal species for migration and localization (Richardson et al. 1995; Leis et al. 2003; Simpson et al. 2004).

The little torrent frog (Amolops torrentis) inhabits mountain streams, at altitudes of 80-780 m, filled on both sides with lush vegetation (Fei et al. 2012). During the breeding season, males prefer to call at sites characterized by high-amplitude stream noise which associates closely with rocks, topographies, vegetation and running water (Fig. S1). A random survey of three typical streams around the field research base at Mt. Diaoluo, indicates that the background noise in the natural habitat of the little torrent frog ranges from 50 to $80 \mathrm{~dB}$, although approximately $80 \%$ of the males $(n=46)$ emit calls at sites for which environmental noise is in the $65-80 \mathrm{~dB}$ range. Moreover, little torrent frogs have also been found to lay eggs at rocky and fast flowing sites and tadpoles also inhabit in such places (Fei et al. 2012). Specifically, little torrent frogs lay eggs in holes or apertures among the rock pile in which the follicles are anchored to the stone or to nearby soils so that the eggs are not washed away by turbulent water. This behavioral preference may thus enhance survival and reproductive success. Furthermore, torrent frogs also can use stones and stream noise to avoid predators and to provide a relatively safe environment for early embryo development. For these reasons noise produced by turbulent water may serve as an indicator of suitable oviposition sites. In view of these considerations, we hypothesized that stream noise may contain information about microhabitat variation useful to females.

The results of a previous study indicate that the dominant frequency of natural male advertisement calls $(4.3 \mathrm{kHz})$ is substantially mismatched with female auditory frequency tuning $(1.6 \mathrm{kHz})$ in little torrent frogs, despite the fact that low-frequency calls with a dominant frequency equal to $1.6 \mathrm{kHz}$ are attractive to females compared to white noise (Zhao et al. 2017). Furthermore, females prefer high-frequency calls (dominant frequency of $4.3 \mathrm{kHz}$ ) to low-frequency calls, regardless of whether they are listening in silent, low-noise or high-noise environments (Zhao et al. 2017). To test the hypothesis that stream noise can be used by females as a cue reflecting information about the microhabitat during mate choice, we compared the females' preferences for stimulus pairs constructed with synthetic male calls (high frequency or low frequency) and stream noise of varied SNR. We predicted that females would prefer calls with high amplitude noise compared with low amplitude noise for each kind of stimulus pair, and that females would prefer calls with noise added compared to those without noise. In addition, we also determined whether stream noise alone is attractive to females.

\section{Materials and methods}

\section{Study site and animal}

During the reproductive season, from April to September in 2015, we collected female little torrent frogs in the Mt. Diaoluo Nature Reserve $\left(18.44^{\circ} \mathrm{N}\right.$ and $\left.109.52^{\circ} \mathrm{E}\right)$, Hainan province, China. Daily temperatures varied between 14 and $25{ }^{\circ} \mathrm{C}$ during this period. Females found in the stream and nearby shrubs were collected (between 1900 and 2200 hours), placed in containers with water and stones from their capture sites, and brought back to the laboratory for testing as described below. In this species, females of sexual maturity are larger than males and the ovulating female has an obviously plump abdomen. Only ovulated frogs were used in the experiments, to ensure that females would respond well to the acoustic stimuli. All individuals were returned to their natural habitat immediately after testing. The frogs were used in the experiments with the permission of the management office of the Mt. Diaoluo nature reserve. All animal procedures were approved by the Animal Care and Use Committee of the Chengdu Institute of Biology, CAS. 


\section{Stimuli}

Sound recording procedures and signal-noise ratio (SNR) assessments

We recorded advertisement calls with a directional microphone (Sennheiser ME66 with K6 power module) connected to a digital recorder (Marantz PMD 660, 16 bit, $44.1 \mathrm{kHz}$ ) from a distance of $1 \mathrm{~m}$. We also measured call sound pressure levels (SPLs) and ambient stream SPLs at the same distance, using an A-weighted sound level meter (AWA 6291, Hangzhou Aihua Instruments Co.). For each male, 6-10 calls were recorded continuously during each recording session, and the peak sound pressure value was recorded for each call. Seven call parameters were analyzed with Adobe Audition 3.0 software, in order to display the natural range of acoustic features. Additional information about sampling procedures and call parameters has been described in detail previously by Zhao et al. (2017). To measure the real vocal amplitude accurately, we subtracted the background from that of the signal using logarithmic computation rules (Weißing 1984), in which

$L_{\text {sig }}=10 \log _{10}\left(10^{(\text {Lsig }+ \text { noise } / 10)}-10^{(\text {Lnoise } / 10)}\right)$,

where $L_{\text {sig+noise }}$ is the total sound pressure level, $L_{\text {noise }}$ is the background noise level alone, and $L_{\text {sig }}$ is the SPL of the signal (Brumm and Zollinger 2011). Then the $\mathrm{dB}$ of signal and noise were transformed to $\mathrm{Pa}$ with this formula: $\mathrm{Le}=20 \log \left(P / P_{0}\right)$, where Le is $\mathrm{dB}$ SPL, $P$ is sound pressure $(\mu \mathrm{Pa})$, and $P_{0}$ is the reference pressure $20 \mu \mathrm{Pa}$. A sample consisting of 40 males recorded from different stream locations was used to determine the SNR range. The results show SNRs range from $1.23: 1$ to $18.81: 1$ in the frogs' natural habitat.

\section{Synthetic stimuli}

It can be difficult to ensure that completely synthesized biological sounds will be perceived by the test species as a natural call. On the other hand, a recording from a wild male frog may not be representative for the local population. In this study, we first chose a typical call whose acoustic features all fell within the natural range (Table S1) and then adjusted several key parameters including the dominant frequency, call duration and the note number, within the average range. Similarly, the background noise from three locations (three samples per location) was used to form a single aggregated noise for the experiments. These sites are representative of natural conditions, insofar as the largest number of vocalizing males aggregate at these sites during the breeding season. Moreover, these sites are typically rocky, hilly and near fast-flowing water which, potentially, could provide benefits for survival and reproduction. All acoustic stimuli were synthesized using Avisoft SAS-Lab Pro (Avisoft Bioacoustics, Berlin) and Adobe Audition 3.0 software (California, USA).

The dominant frequency of the high and low frequency call stimuli were 4.3 and $1.6 \mathrm{kHz}$, respectively. The noise presentation gated on and off with the call stimuli with a 5 -s inter-stimulus interval. To create stimulus pairs for the experiments, the SNR was set to either $2: 1$ or $8: 1$. Three stimulus categories were used: (1) high dominant frequency call with no noise added (HN), high dominant frequency call with low amplitude noise added (HL: signal/ noise $=8: 1)$ and high dominant frequency call with high amplitude noise added (HH: signal/noise $=2: 1$ ) (Fig. 1ac), (2) low dominant frequency call with no noise added (LN), low dominant frequency call with low amplitude noise added (LL: signal/noise $=8: 1$ ) and low dominant frequency call with high amplitude noise added (LH: sig$\mathrm{nal} /$ noise $=2: 1)($ Fig. 1d-f), and (3) running water (RW), white noise (WN) and silence (S). A total of eight stimulus pairs were constructed using these three categories of stimuli, as described below (Tables 1,2).

\section{Phonotaxis experiments}

The three categories of stimulus pairs described above were used in experiments 1-3, respectively. Experiment 1 and experiment 2 were conducted in order to determine whether stream noise provides salient information to female little torrent frogs. Two stimulus pairs in experiment 3 were utilized in order to determine whether stream noise alone provides information salient to females.

We conducted standard two-speaker phonotaxis tests in a sound-attenuating chamber $[2.2(\mathrm{~L}) \times 1.5(\mathrm{~W}) \times 1.5$ (H) m]. Females were placed in the center of the chamber while the stimulus pairs were broadcast antiphonally from speakers (SME-AFS, Saul Mineroff Electronics, Elmont, NY, USA) placed in the center of each wall opposite one another such that the peak amplitude of each test call was $80 \mathrm{~dB}$ SPL (re $20 \mu \mathrm{Pa}$ ), and the peak amplitude of the running water (i.e., stream noise) was $75 \mathrm{~dB}$ within the natural range. The subject's choice and response time were noted when a female approached within $10 \mathrm{~cm}$ of one of the two speakers as long as the female did not follow the walls of the chamber. A female was considered to have failed to meet our response criterion if she was motionless or spent more than $10 \mathrm{~min}$ roaming the arena without approaching a speaker. In this case the response time was recorded as $10 \mathrm{~min}$. Prior to the experiment, the frogs were held for $2 \mathrm{~h}$ in the lab to eliminate the possible effects of previous exposure to the natural chorus. To control for potential side biases, we randomized the speaker assignments for each stimulus pair. The experimental order was 

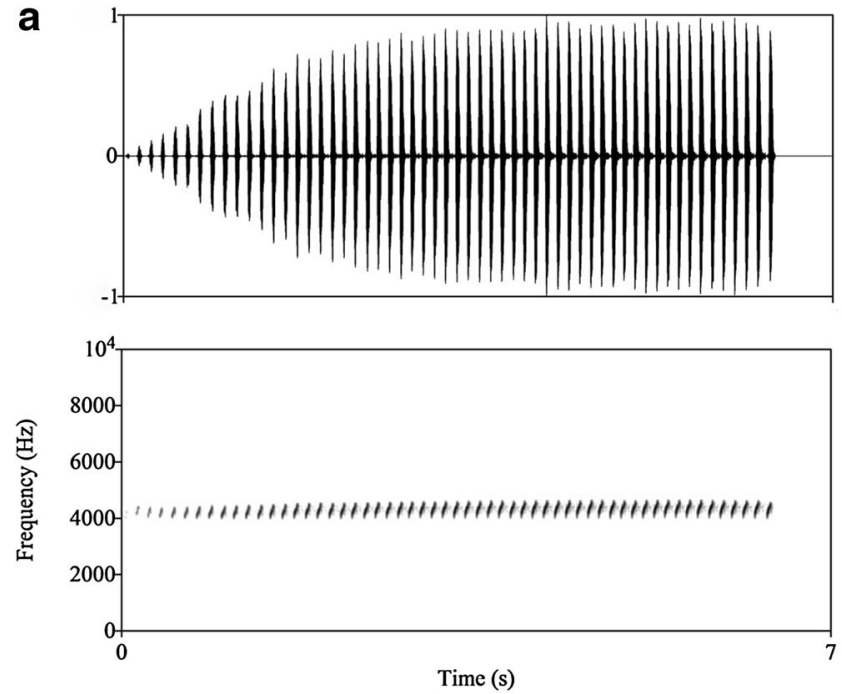

C
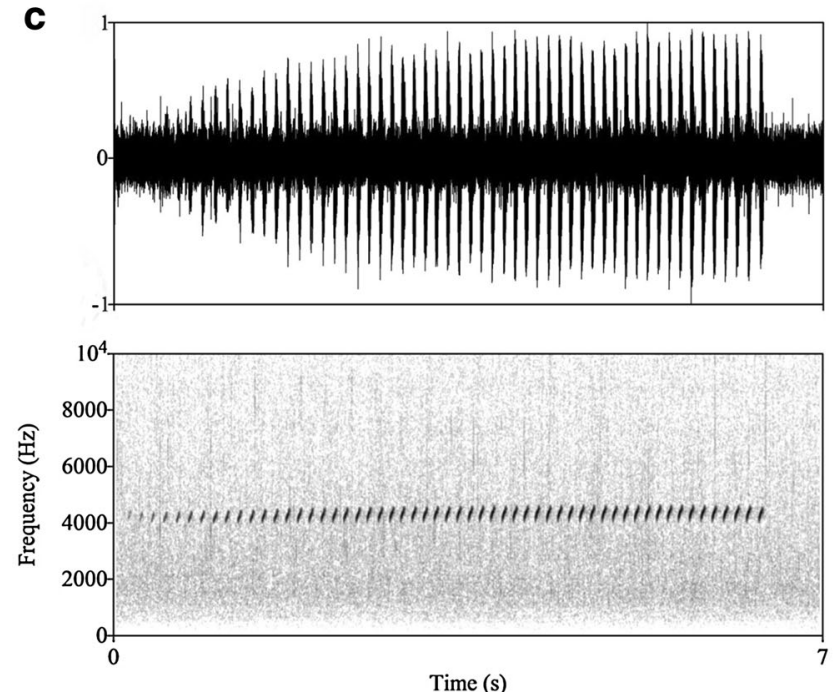

e
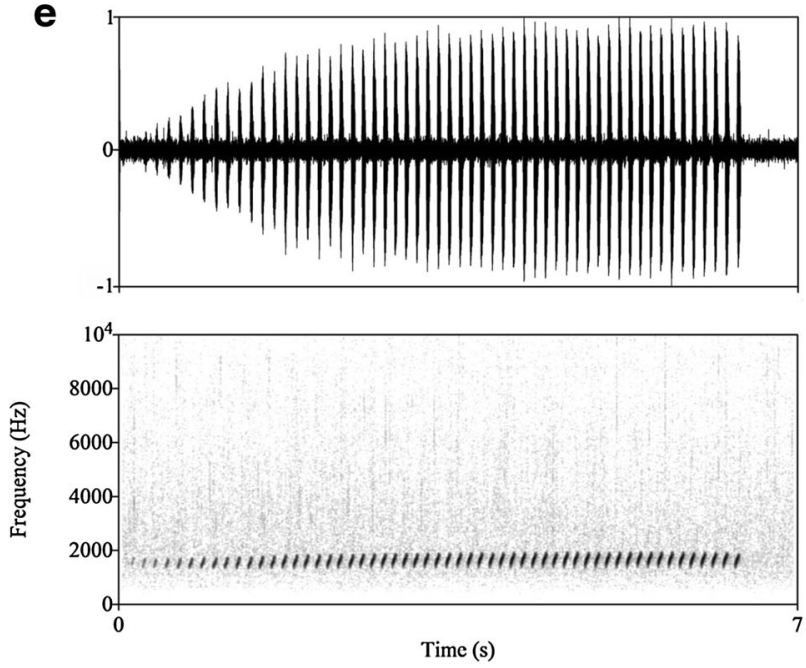

b
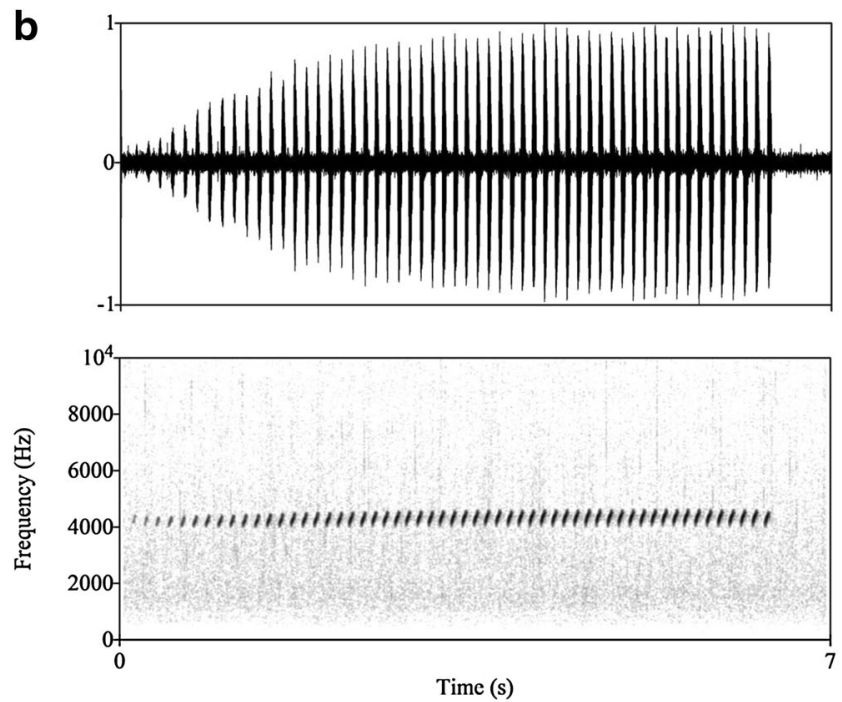

d
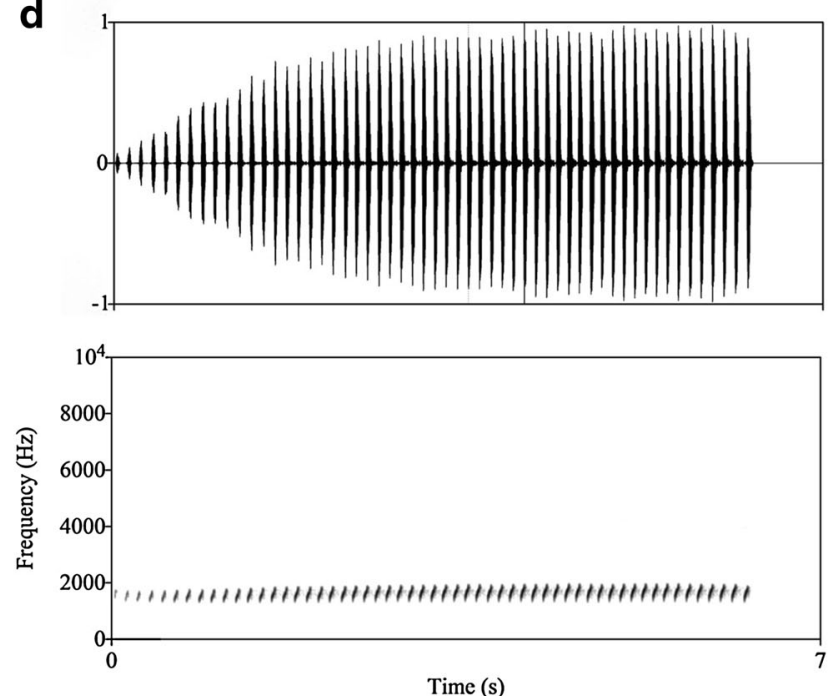

f
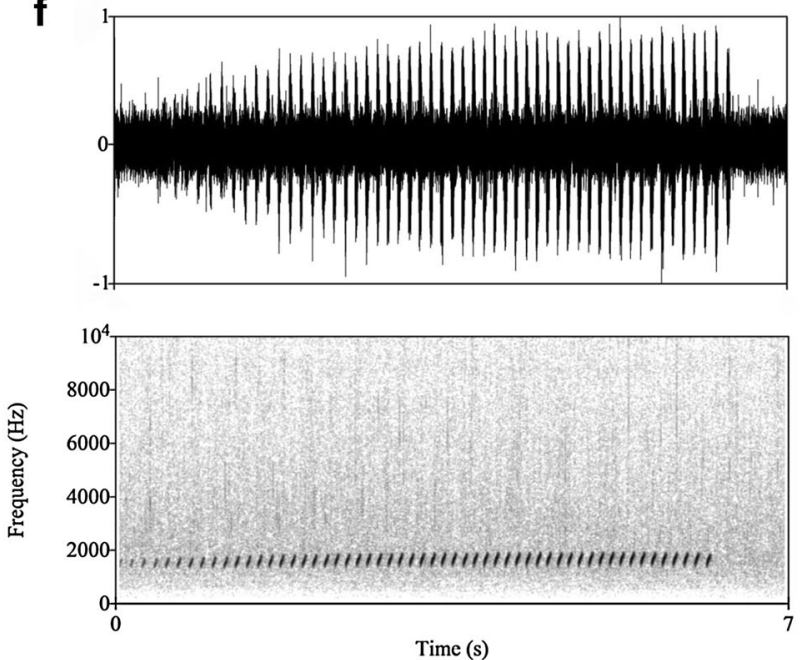
4Fig. 1 Waveforms (top panels) and spectrograms (bottom panels) of the six acoustic stimuli used in the female phonotaxis experiments. Experiment 1: a (HN), b (HL), c (HH); Experiment 2: d (LN), e (LL), f $(\mathrm{LH}) . H N$ high dominant frequency call with no noise added, $H L$ high dominant frequency call with low amplitude noise added, $H H$ high dominant frequency call with high amplitude noise added, $L N$ low dominant frequency call with no noise added, $L L$ low dominant frequency call with low amplitude noise added, $L H$ low dominant frequency call with high amplitude noise added

also random, insofar as previous experience may also affect the responses of the frogs. Females were never tested more than once in the same experiment. The phonotaxis results showed that there were no side biases.

\section{Statistical analysis}

Pearson chi-square was used to evaluate differences in female preference for the stimuli $(n \geq 40)$ used in this study and for differences in the proportion of females who did not meet the phonotaxis response criterion. Fisher's exact test was used to examine female preferences for call pairs with the same fundamental frequency but varying noise added $(n<40)$. The Mann-Whitney rank sum test was used to compare female response time between the noise vs no added noise stimulus pairs and stimuli with high amplitude noise vs low amplitude noise in experiment 1 and experiment 2. All statistical analyses were carried out with SPSS 16.0 software (SPSS Inc., USA) and sigmaplot 11 software (Systat Software Inc., San Jose, USA). A significance level of $p<0.05$ was used in all comparisons.

\section{Results}

\section{Female call preferences}

Female choices for the phonotaxis experiments comparing all pairs of the eight test calls are shown in Table 2. In experiment 1 (i.e., comparing call stimuli of high dominant
Table 2 Summary of outcomes from the phonotaxis tests of experiments $1-3$

\begin{tabular}{|c|c|c|c|c|c|c|}
\hline \multirow[t]{2}{*}{ Experiment } & \multirow[t]{2}{*}{ Test } & \multicolumn{2}{|c|}{ Stimuli } & \multicolumn{2}{|c|}{ Choices } & \multirow[t]{2}{*}{$p$} \\
\hline & & A & B & A & B & \\
\hline \multirow[t]{3}{*}{1} & 1 & HL & $\mathrm{HN}$ & 22 & 20 & 0.663 \\
\hline & 2 & $\mathrm{HH}$ & $\mathrm{HN}$ & 19 & 22 & 0.508 \\
\hline & 3 & $\mathrm{HH}$ & HL & 18 & 9 & 0.014 \\
\hline \multirow[t]{3}{*}{2} & 4 & LL & $\mathrm{LN}$ & 19 & 22 & 0.508 \\
\hline & 5 & LH & $\mathrm{LN}$ & 20 & 22 & 0.663 \\
\hline & 6 & LH & LL & 16 & 9 & 0.044 \\
\hline \multirow[t]{2}{*}{3} & 7 & RW & WN & 20 & 20 & 1.000 \\
\hline & 8 & RW & $\mathrm{S}$ & 16 & 24 & 0.074 \\
\hline
\end{tabular}

The choices represent the number of females attracted to each stimulus in each experiment in each test. Statistical $p$ values are the probability of rejecting the null hypothesis using the Pearson chisquare or Fisher's exact tests

$H N$ high dominant frequency call with no noise added, $H L$ high dominant frequency call with low amplitude noise added, $H H$ high dominant frequency call with high amplitude noise added, $L N$ low dominant frequency call with no noise added, $L L$ low dominant frequency call with low amplitude noise added, $L H$ low dominant frequency call with high amplitude noise added, $R W$ running water, $S$ silence, $W N$ white noise

frequency with no noise, low amplitude noise or high amplitude noise added), both the proportion of subjects choosing $\mathrm{HL}$ vs $\mathrm{HN}$ and that of $\mathrm{HH}$ vs $\mathrm{HN}$ did not differ significantly (Pearson chi-square: test $1, \chi^{2}=0.19$, $p=0.663$; test $\left.2, \chi^{2}=0.439, p=0.508\right)$; however, females preferred HH to HL (Fisher's exact test: $p=0.014$ ) (Table 2). In experiment 2 , call stimuli of low dominant frequency were used with no noise, low amplitude noise or high amplitude noise added (i.e., LN, LL and LH stimuli). For experiment 2, we found that female call preferences were consistent with the results of experiment 1. Thus, female preferences between call pairs with the same frequency but varying noise added were not significantly different in LL vs LN and in LH vs LN (Pearson chisquare: test $4, \chi^{2}=0.439, p=0.508$; test $5, \chi^{2}=0.19$,
Table 1 All eight stimulus pairs constructed in this study

\begin{tabular}{llllll}
\hline Stimulus pairs & Stimulus 1 & & & Stimulus 2 \\
\cline { 2 - 3 } \cline { 5 - 6 } & Frequency type & Signal/noise & & Frequency type & Signal/noise \\
\hline 1 & High-frequency & $8: 1$ & & High-frequency & - \\
2 & High-frequency & $2: 1$ & & High-frequency & - \\
3 & High-frequency & $2: 1$ & & High-frequency & $8: 1$ \\
4 & Low-frequency & $8: 1$ & & Low-frequency & - \\
5 & Low-frequency & $2: 1$ & & Low-frequency & - \\
6 & Low-frequency & $2: 1$ & & Low-frequency & $8: 1$ \\
7 & Running water & - & & White noise & - \\
8 & Running water & - & Silence & - \\
\hline
\end{tabular}


$p=0.663$ ), but LH was more attractive than LL (Fisher's exact test: $p=0.044$ ) (Table 2).

\section{Female response time}

Female response times in experiment 1 and experiment 2 for all pair comparisons of the six test calls are shown in Fig. 2. In experiment 1 , female response time was significantly longer for the high-frequency stimulus pairs of HL vs $\mathrm{HN}$ and that of $\mathrm{HH}$ vs $\mathrm{HN}$ (median $8 \mathrm{~min}$ ) compared to that of HH vs HL (median 4.5 min) (Mann-Whitney rank sum test: $U=2192.5, p=0.037)$. Likewise, female response time was longer for the low-frequency stimulus pairs of LL vs LN and that of LH vs LN (median $10 \mathrm{~min}$ ) compared to that of LH vs LL (median $8 \mathrm{~min}$ ), although these differences were not statistically significant (MannWhitney rank sum test: $U=2523, p=0.089$ ).

\section{Stream noise in the absence of advertisement calls}

In experiment 3 , the proportion of responsive females that chose the sound of running water (RW) over the white noise (WN) or silence (S) stimuli did not differ significantly (Pearson chi-square: test $7, \chi^{2}=0, p=1.0$; test 8 , $\chi^{2}=3.2, p=0.074$ ) (Table 2). Furthermore, over $50 \%$ of the females failed to meet our response criterion in this experiment, which is significantly higher than the proportion in experiment 1 (proportion: 40\%; Pearson chi-square: $\chi^{2}=6.0, p=0.014$ ) and the proportion in experiment 2 (proportion: $45 \%$; Pearson chi-square: $\chi^{2}=2.4$,

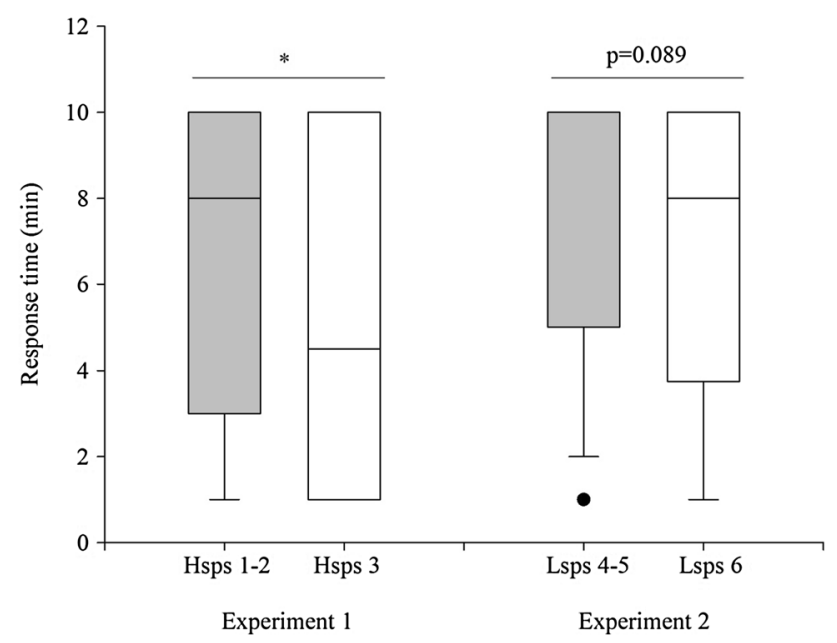

Fig. 2 Female response times in phonotaxis experiment 1 (Hsps 1-2, $n=146$; Hsps $3, n=38$ ) and experiment 2 (Lsps 4-5, $n=159$; Lsps $6, n=38$ ). Box plots show the median response with interquartile range and the 25 th and 75 th percentile. $* p<0.05$. Hsps high-frequency stimulus pairs of experiment 1 , Lsps low-frequency stimulus pairs of experiment 2 $p=0.076$ ) (Fig. 3). These results suggest that the sound of running water is not in itself attractive to female frogs.

\section{Discussion}

It has been widely known that stream noise can constrain sound communication by interfering with the propagation of acoustic signals and the receiver's perception of the signal, and that these phenomena can drive the evolution of sexual signals and perceptual systems (Brumm and Slabbekoorn 2005; Feng et al. 2006; Shen et al. 2008). It is also widely known that many species from varying taxa show remarkable adaptations or behavioral plasticity for coping with noise (Haddad and Giaretta 1999; Boeckle et al. 2009; Shieh et al. 2012; Caldart et al. 2016). However, there is little evidence indicating that animals use the sound from fast-flowing streams as a signal. In the present study, female little torrent frogs showed a preference for calls with high amplitude noise compared with low amplitude noise in tests involving both high dominant frequency and low dominant frequency calls while stream noise itself had no attractiveness. These results suggest that stream noise is a cue that can provide information salient to females of streamside breeding species when listening to male calls.

In many species, males vocalize to attract mates and their calls serve as acoustic beacons to conspecific females as well as to eavesdropping predators and parasites (Tuttle and Ryan 1981; Tuttle et al. 1985; Dapper et al. 2011). Prey can use ambient noise to avoid predators; for instance, masking background noise may benefit prey species because it can reduce the foraging success of predators (Barber et al. 2009). Apart from natural biotic noise,

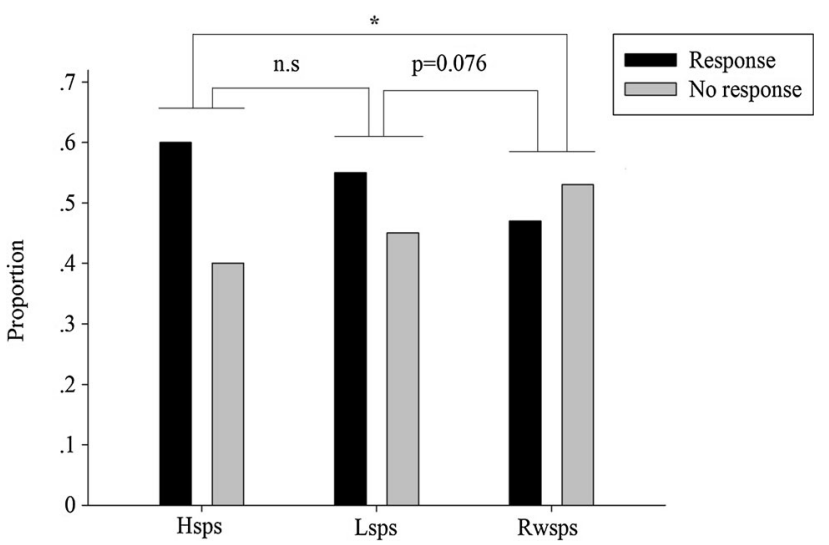

Fig. 3 Proportions of females that met and did not meet the phonotaxis response criterion in the Hsps, Lsps and Rwsps experiments (Hsps, total $n=184$; Lsps, total $n=197$; Rwsps, total $n=171) .{ }^{*} p<0.05$. n.s. not statistically significant, Hsps highfrequency stimulus pairs of experiment 1, Lsps low-frequency stimulus pairs of experiment 2, Rwsps the running water stimulus pairs of experiment 3 
animals also can make use of abiotic noise as a signal in orientation. Studies on marine mammals suggest that ocean noise caused by waves or currents plays an important role in migration and orientation behavior (Richardson et al. 1995). Moreover, many reproductive sites such as burrows, holes, nests and hides provide safety and security for mating, egg laying or the raising of offspring. Information about these microhabitats can be encoded by sounds. For instance, male Emei music frog (Babina daunchina) calls convey information about the geometry of nest burrows which is salient to females (Cui et al. 2012). Interestingly, male little torrent frogs often vocalize at rocky and fastflowing sites where amplexus and spawning occur in hidden holes and gaps, while females often inhabit the forested areas along the sides of streams during the breeding season. Thus, it is possible that stream noise can be beneficial for avoiding predators and orienting in this stream-breeding species.

Surprisingly, in the present study, female torrent frog preferences were not significantly different in either the $\mathrm{HH}$ vs $\mathrm{HN}$ and $\mathrm{HL}$ vs $\mathrm{HN}$ stimulus pairs, or the LH vs LN and LL vs LN stimulus pairs (Table 2). Male little torrent frogs never emit sounds far away from flowing stream water in their natural habitat. For this reason females would not normally hear male calls in the absence of stream noise at the distance ( $1 \mathrm{~m}$ range) used in the phonotaxis studies here. Thus, it is likely that the HN and LN sounds functioned as novel stimuli for female frogs in our study.

Many studies indicate that songbirds and frogs are more sensitive initially to the playback of a novel stimulus. In such cases the animals manifest changes in many aspects of observable behaviors such as staying closer to the speaker in playback experiments or flying short distances more frequently (Davis 1987; Blanchard 1941; Verner and Milligan 1971; Owen and Perrill 1998; Kroodsma 2015). In the absence of stream noise, higher SNR calls are easier to process and easier for females to perceive, although this condition does not normally occur in their natural habitat. The response to HN and LN stimuli would be enhanced by sensitization to novel stimuli and by the advantage which such stimuli would have for female perception. This idea is supported by the fact that female response times were longer in tests $1-2$ than in test 3 , and longer in tests $4-5$ than in test 6 (Fig. 2), implying that female choice is more difficult when it involves novel calls with no added noise compared to female choice involving call pairs in which both stimuli contain added stream noise, since such calls are typical in the natural habitat.

Growing research also suggests that sexual choice may not be consistent across females, and often fluctuates greatly depending on the environmental context (Edward and Gilburn 2007; Pfennig 2007; Bussiere et al. 2008; Fricke et al. 2009; Robinson et al. 2012). In this study, male calls were much louder than stream noise, so females positioned sufficiently far from the calling site would likely hear the male calls with little or no background noise. The behavioral strategy of females (i.e., female torrent frog preferences were not significantly different in either the $\mathrm{HH}$ vs $\mathrm{HN}$ and HL vs HN stimulus pairs, or the LH vs LN and LL vs LN stimulus pairs) may reflect trade-offs between the advantages of seeking nearby reproduction sites identified by noise cues and the advantages of seeking new reproduction sites. Put another way, noise associated with the calls of nearby males can be informative; however, there may be advantages for females in selecting males whose calls are not associated with stream noise because they are not close by. Further study is needed to determine whether the preferences observed here for stimulus pairs with the same fundamental frequency in noise vs silence reflect such context-dependent strategies.

Taken together, our results demonstrate that stream noise can be a cue that is salient to females. Stream noise in the context of male vocalization may inform females about microhabitats in streamside species. Our data also provide experimental evidence supporting the idea that female mate choice is influenced by variation in ecological factors not strictly related to male phenotypes. Ecological variation is common in the field. Therefore, this work can increase our understanding of how sexual selection influences female perception of mate attractiveness in complex and diverse environments.

Acknowledgements We thank Yue Yang for her help during the experiments. This work was supported by Youth Innovation Promotion Association CAS, CAS "Light of West China" Program, National Natural Science Foundation of China (31270042) and Youth Professor Project of CIB (Y3B3011).

\section{References}

Barber JR, Crooks KR, Fristrup K (2009) The costs of chronic noise exposure for terrestrial organisms. Trends Ecol Evol 25:180-189. doi:10.1016/j.tree.2009.08.002

Bernal XE, Rand AS, Ryan MJ (2007) Sexual differences in the behavioral response of túngara frogs, Physalaemus pustulosus, to cues associated with increased predation risk. Ethology 113:755-763. doi:10.1111/j.1439-0310.2007.01374.x

Blanchard BD (1941) The white-crowned sparrows (Zonotrichia leucophrys) of the Pacific seaboard: environment and annual cycle. University of California Press, California, pp 1-178

Boeckle M, Preininger D, Hödl W (2009) Communication in noisy environments i: Acoustic signals of Staurois latopalmatus Boulenger 1887. Herpetologica 65:154-165. doi:10.1655/07071R1.1

Brumm H, Naguib M (2009) Environmental acoustics and the evolution of bird song. Adv Stud Behav 40:1-33. doi:10.1016/ S0065-3454(09)40001-9

Brumm H, Slabbekoorn H (2005) Acoustic communication in noise. Adv Stud Behav 35:151-209. doi:10.1016/S00653454(05)35004-2 
Brumm H, Zollinger SA (2011) The evolution of the Lombard effect: 100 years of psychoacoustic research. Behaviour 148:1173-1198. doi:10.1163/000579511X605759

Bussiere LF, Hunt J, Stölting KN, Jennions MD, Brooks R (2008) Mate choice for genetic quality when environments vary: suggestions for empirical progress. Genetica 134:69-78. doi:10.1007/s10709-007-9220-z

Caldart VM, Iop S, Lingnau R, Cechin SZ (2016) Communication in a noisy environment: short-term acoustic adjustments and the underlying acoustic niche of a Neotropical stream-breeding frog. Acta Ethol 19:151-162. doi:10.1007/s10211-016-0235-2

Chan AAYH, Giraldo-Perez P, Smith S, Blumstein DT (2010) Anthropogenic noise affects risk assessment and attention: the distracted prey hypothesis. Biol Lett 6:458-461. doi:10.1098/ rsbl.2009.1081

Cui JG, Tang YZ, Narins PM (2012) Real estate ads in Emei music frog vocalizations: female preference for calls emanating from burrows. Biol Lett 8:337-340. doi:10.1098/rsbl.2011.1091

Dapper AL, Baugh AT, Ryan MJ (2011) The sounds of silence as an alarm cue in túngara frogs, Physalaemus pustulosus. Biotroppica 43:380-385. doi:10.1111/j.1744-7429.2010.00707.x

Davis MS (1987) Acoustically mediated neighbor recognition in the North American bullfrog, Rana catesbeiana. Behav Ecol Sociobiol 21:185-190. doi:10.1007/BF00303209

Edward DA, Gilburn AS (2007) The effect of habitat composition on sexual conflict in the seaweed flies Coelopa frigida and $C$. pilipes. Anim Behav 74:343-348. doi:10.1016/j.anbehav.2006.07.023

Fei L, Ye CY, Jiang JP (2012) Colored atlas of Chinese amphibians and their distributions. Sichuan Publishing House of Science and Technology, Chengdu

Feng AS, Schul J (2007) Sound processing in real-world environments. In: Narins PM, Feng AS, Fay RR, Popper AN (eds) Hearing and sound communication in amphibians. Springer, New York, pp 323-350

Feng AS, Narins PM, Xu CH, Lin WY, Yu ZL, Qiu Q, Xu ZM, Shen JX (2006) Ultrasonic communication in frogs. Nature 440:333-336. doi:10.1038/nature04416

Francis CD, Ortega CP, Cruz A (2009) Noise pollution changes avian communities and species interactions. Curr Biol 19:1415-1419. doi:10.1016/j.cub.2009.06.052

Fricke C, Perry J, Chapman T, Rowe L (2009) The conditional economics of sexual conflict. Biol Lett 5:671-674. doi:10.1098/ rsbl.2009.0433

Fuller RA, Warren PH, Gaston KJ (2007) Daytime noise predicts nocturnal singing in urban robins. Biol Lett 3:368-370. doi:10. 1098/rsbl.2007.0134

Gerhardt HC, Klump GM (1988) Phonotactic responses and selectivity of barking treefrogs (Hyla gratiosa) to chorus sounds. J Comp Physiol A 163:795-802. doi:10.1007/BF00604056

Grafe TU (1999) A function of synchronous chorusing and a novel female preference shift in an anuran. Proc R Soc Lond B 266:2331-2336. doi:10.1098/rspb.1999.0927

Haddad CFB, Giaretta AA (1999) Visual and acoustic communication in the Brazilian torrent frog, Hylodes asper (Anura: Leptodactylidae). Herpetologica 55:324-333. http://www.jstor.org/stable/3893226

Halfwerk W, Page RA, Taylor RC, Wilson PS, Ryan MJ (2014) Crossmodal comparisons of signal components allow for relative-distance assessment. Curr Biol 24:1751-1755. doi:10.1016/ j.cub.2014.05.068

Kroodsma D (2015) The singing life of birds: the art and science of listening to birdsong. Houghton Mifflin Harcourt, Houghton

Leis JM, Carson-Ewart BM, Hay AC, Cato DH (2003) Coral-reef sounds enable nocturnal navigation by some reef-fish larvae in some places and at some times. J Fish Biol 63:724-737. doi:10. 1046/j.1095-8649.2003.00182.x
Linhart P, Slabbekoorn H, Fuchs R (2012) The communicative significance of song frequency and song length in territorial chiffchaffs. Behav Ecol 23:1338-1347. doi:10.1093/beheco/ $\operatorname{ars} 127$

Lohr B, Wright TF, Dooling RJ (2003) Detection and discrimination of natural calls in masking noise by birds: estimating the active space of a signal. Anim Behav 65:763-777. doi:10.1006/anbe. 2003.2093

Love EK, Bee MA (2010) An experimental test of noise-dependent voice amplitude regulation in Cope's grey treefrog, Hyla chrysoscelis. Anim Behav 80:509-515. doi:10.1016/j.anbehav. 2010.05.031

Marler P, Slabbekoorn H (2004) Nature's music: the science of birdsong. Elsevier Academic Press, San Diego

Owen PC, Perrill SA (1998) Habituation in the green frog, Rana clamitans. Behav Ecol Sociobiol 44:209-213. doi:10.1007/ s002650050533

Pfennig KS (2007) Facultative mate choice drives adaptive hybridization. Science 318:965-967. doi:10.1126/science.1146035

Rabin LA, Greene CM (2002) Changes to acoustic communication systems in human-altered environments. J Comp Psychol 116:137-141. doi:10.1037/0735-7036.116.2.137

Richardson WJ, Greene CR Jr, Malme CI, Thomson DH (1995) Marine mammals and noise. Academic Press, San Diego

Robinson MR, Sander van Doorn G, Gustafsson L, Qvarnström A (2012) Environment-dependent selection on mate choice in a natural population of birds. Ecol Lett 15:611-618. doi:10.1111/j. 1461-0248.2012.01780.x

Schaub A, Ostwald J, Siemers BM (2008) Foraging bats avoid noise. J Exp Biol 211:3174-3180. doi:10.1242/jeb.022863

Shen JX, Feng AS, Xu ZM, Yu ZL, Arch VS, Yu XJ, Narins PM (2008) Ultrasonic frogs show hyperacute phonotaxis to the female's courtship calls. Nature 453:914-916. doi:10.1038/ nature 06719

Shieh BS, Liang SH, Chen CC, Loa HH, Liao CY (2012) Acoustic adaptations to anthropogenic noise in the cicada Cryptotympana takasagona Kato (Hemiptera: Cicadidae). Acta Ethol 15:33-38. doi:10.1007/s10211-011-0105-x

Simpson SD, Meekan MG, McCauley R, Jeffs A (2004) Attraction of settlement stage coral reef fish to reef noise. Mar Ecol Prog Ser 276:263-268. doi:10.3354/meps276263

Sinsch U (1990) Migration and orientation in anuran amphibians. Ethol Ecol Evol 2:65-79. doi:10.1080/08927014.1990.9525494

Slabbekoorn H, Peet M (2003) Ecology: birds sing at a higher pitch in urban noise. Nature 424:267. doi:10.1038/424267a

Stansbury A, Deecke V, Götz T, Janik VM (2016) Potential uses of anthropogenic noise as a source of information in animal sensory and communication systems. In: Proper AN, Hawkis A (eds) Advances in experimental medicine and biology. Springer, New York, pp 1105-1111

Tuttle MD, Ryan MJ (1981) Bat predation and the evolution of frog vocalizations in the Neotropics. Science 214:677-678. doi:10. 1126/science.214.4521.677

Tuttle MD, Ryan MJ, Belwood JJ (1985) Acoustical resource partitioning by two species of phyllostomid bats (Trachops cirrhosus and Tonatia sylvicola). Anim Behav 33:1369-1370

Tyack P (1998) Acoustic communication under the sea. In: Hopp SL, Evans CS (eds) Animal acoustic communication. Springer, Heidelberg, pp 163-220

Verner J, Milligan MM (1971) Responses of male white-crowned sparrows to playback of recorded songs. Condor 73:56-64. doi: $10.2307 / 1366124$

Weißing H (1984) Pegelgrößen. In: Fasold W, Kraak W, Schirmer W (eds) Taschenbuch Akustik. VEB Verlag Technik, Berlin, pp 380-387 
Wells KD, Schwartz JJ (2007) The behavioral ecology of anuran communication. In: Narins PM, Feng AS, Fay RR, Popper AN (eds) Hearing and sound communication in amphibians. Springer, New York, pp 44-86

Wiley RH, Richards DG (1982) Adaptations for acoustic communication in birds: sound transmission and signal detection. In:
Kroodsma DH, Miller EH (eds) Acoustic communication in birds. Academic Press, New York, pp 131-181

Zhao LH, Wang JC, Yang Y, Zhu BC, Brauth SE, Tang YZ, Cui JG (2017) An exception to the matched filter hypothesis: a mismatch of male call frequency and female best hearing frequency in a torrent frog. Ecol Evol 7:419-428. doi:10.1002/ece3.2621 